\title{
Influence of Hydrothermal Temperature on Phosphorus Recovery Efficiency of Porous Calcium Silicate Hydrate
}

\author{
Wei Guan, Fangying Ji, Qingkong Chen, Peng Yan, and Weiwei Zhou \\ Key Laboratory of Three Gorges Reservoir Region's Eco-Environment of Ministry of Education, Chongqing University, \\ Chongqing 400045, China \\ Correspondence should be addressed to Fangying Ji; jfy@cqu.edu.cn
}

Received 2 November 2012; Revised 20 December 2012; Accepted 3 January 2013

Academic Editor: Wen Zeng

Copyright (C) 2013 Wei Guan et al. This is an open access article distributed under the Creative Commons Attribution License, which permits unrestricted use, distribution, and reproduction in any medium, provided the original work is properly cited.

Porous calcium silicate hydrate (PCSH) was synthesized by carbide residue and white carbon black. The influence of hydrothermal temperature on phosphorus recovery efficiency was investigated by Field Emission Scanning Electron Microscopy (FESEM), Brunauer-Emmett-Teller (BET), and X-Ray Diffraction (XRD). Hydrothermal temperature exerted significant influence on phosphorus recovery performance of PCSH. Hydrothermal temperature $170^{\circ} \mathrm{C}$ for PCSH was more proper to recover phosphorus. PCSH could recover phosphorus with content of $18.51 \%$. The law of $\mathrm{Ca}^{2+}$ and $\mathrm{OH}^{-}$release was the key of phosphorus recovery efficiency, and this law depended upon the microstructure of PCSH. When the temperature of synthesis reached to $170^{\circ} \mathrm{C}$, the reactions between $\mathrm{CaO}$ and amorphous $\mathrm{SiO}_{2}$ were more efficient. Solubility of $\mathrm{SiO}_{2}$ was a limiting factor.

\section{Introduction}

Phosphorus recovery from wastewater in the form of hydroxyapatite is an effective method [1]. However, the optimal pH value for the formation of hydroxyapatite is in the range of $10.5 \sim 12.5$ [2]. But this $\mathrm{pH}$ value is too high to biochemical treatment system where the $\mathrm{pH}$ value is located between 6.0 and $9.0[3]$.

Phosphorus recovery on the condition of alkalescency not only decreased the significant competition between carbonate and calcium, but also decreased the cost of chemical treatment and increased the effective phosphorus composition of the final products [4]. To address these issues, calcium silicate hydrate was introduced [5]. The existing researches showed that calcium silicate hydrate could be considered as a very attractive and promising material to remove phosphorus from wastewater when compared with the common natural materials [6]. Because calcium silicate hydrate could release $\mathrm{Ca}^{2+}$ and $\mathrm{OH}^{-}$[7], $\mathrm{Ca}^{2+}, \mathrm{OH}^{-}$and $\mathrm{PO}_{4}{ }^{3-}$ in the solution form a condition locally for the growth of HAP, which could grow with $\mathrm{pH}=8.0-9.0$. In order to achieve this goal, it is necessary to find a process condition to prepare calcium silicate hydrate.

From a theoretical and practical point of view, the synthesis, properties, and structure of calcium silicate hydrate have been analyzed in detail [8-11]. Dynamic hydrothermal synthesis is a common method to prepare calcium silicate hydrate $[12,13]$. Hydrothermal temperature is one of the most important factors, which determine the microstructure of calcium silicate hydrate [14]. Prophase researches showed that the difference of microstructure has an effect on the phosphorus recovery performance of calcium silicate hydrate. However, the bottleneck problem was that it was hard to determine the appropriate hydrothermal temperature for the preparation of the calcium silicate hydrate which possesses the phosphorus recovery performance.

The main aim of the research is to find a proper hydrothermal temperature for calcium silicate hydrate to recover phosphorus. The originality and importance of this paper are highlighted by the following three points.

(1) PCSH was synthesized by carbide residue and white carbon black with a dynamic hydrothermal method. The influence of hydrothermal temperature on phosphorus recovery performance was investigated.

(2) The relationship between pore structure and the law of $\mathrm{Ca}^{2+}$ and $\mathrm{OH}^{-}$release was established by Avrami kinetic model. 
TABLE 1: Chemical components of carbide residue and white carbon black.

\begin{tabular}{lccccccccccc}
\hline & \multicolumn{1}{c}{ Chemical components (contents) $/ \%$} \\
& $\mathrm{CaO}$ & $\mathrm{SiO}_{2}$ & $\mathrm{Al}_{2} \mathrm{O}_{3}$ & $\mathrm{SO}_{2}$ & $\mathrm{MgO}$ & $\mathrm{Fe}_{2} \mathrm{O}_{3}$ & $\mathrm{SrO}$ & $\mathrm{NaOH}$ & $\mathrm{CuO}$ & $\mathrm{H}_{2} \mathrm{O}$ \\
\hline Carbide residue & 79.34 & 3.57 & 2.14 & 1.22 & 0.62 & 0.21 & 0.26 & - & - \\
White carbon black & 0.08 & 97.46 & 0.16 & 1.82 & - & 0.03 & - & 0.29 & 0.02 & 0.14 \\
\hline
\end{tabular}

(3) The mechanism of phosphorus recovery was studied by FESEM, BET, and XRD on the basis of an in-depth critical investigation.

\section{Materials and Methods}

2.1. Preparation of PCSH. PCSH was synthesized with carbide residue (providing $\mathrm{Ca}$ ) and white carbon black (providing $\mathrm{Si}$ ). Carbide residue (calcareous, hoar, and powdery) was obtained from Chongqing Changshou Chemical Co. Ltd. and calcined at $700^{\circ} \mathrm{C}$ for $2 \mathrm{~h}$. White carbon black (particles present spherical with homogeneous diameter) was purchased from Chongqing Jianfeng chemical Co. Ltd. Chemical constituents of carbide residue and white carbon black are shown in Table 1. The phosphorus solution was adjusted by adding $\mathrm{KH}_{2} \mathrm{PO}_{4}$ (Analytical reagent, Chongqing Boyi Chemical reagent Co. Ltd.) to prepare solution with initial phosphorus concentration of $100 \mathrm{mg} / \mathrm{L}$. The above materials and chemicals were placed into sealed bottles for storage.

Carbide residue and white carbon black were mixed, and the $\mathrm{Ca} / \mathrm{Si}$ molar ratios were controlled at 1.6:1. The mixture was then added to prepared slurries. The slurry was hydrothermally reacted at $110^{\circ} \mathrm{C}, 140^{\circ} \mathrm{C}, 170^{\circ} \mathrm{C}$, and $200^{\circ} \mathrm{C}$, respectively, and the reaction time was $6 \mathrm{~h}$. The samples were taken out when the temperature was reduced to the natural condition. The hydrothermal reaction was carried out with a liquid/solid ratio of 30 . The obtained products were dried at $105^{\circ} \mathrm{C}$ for $2 \mathrm{~h}$, and then were ground through a sieve of 200 meshes. The prepared samples that were hydrothermally reacted at $110^{\circ} \mathrm{C}, 140^{\circ} \mathrm{C}, 170^{\circ} \mathrm{C}$, and $200^{\circ} \mathrm{C}$ were denoted as PCSH: $110^{\circ} \mathrm{C}, \mathrm{PCSH}: 140^{\circ} \mathrm{C}, \mathrm{PCSH}: 170^{\circ} \mathrm{C}$, and PCSH: $200^{\circ} \mathrm{C}$, respectively.

2.2. Evaluation of Phosphorus Recovery Performance. Firstly, synthetic solution $(1 \mathrm{~L})$ was added into several bottles. $4 \mathrm{~g}$ of samples were added to these bottles, respectively, and shaken at $40 \mathrm{r} / \mathrm{min}$ under controlled temperature conditions $\left(20^{\circ} \mathrm{C}\right)$. Phosphorus concentration of supernatant was measured according to the molybdenum blue ascorbic acid method (the relative error of data is $0.3 \%$ ) with a Unico spectrophotometer (UV-2012PCS, Shanghai Unico Instruments Co., Ltd., China). The solid samples were then separated from the removed synthetic solution with the addition of samples after reaction. Finally, the produced sediments were separated from removed synthetic solution, dried, and weighted. Phosphorus was contented by

$$
P=\frac{\left(C_{0}-C_{t}\right) \times v}{w} \times 100 \%,
$$

where $C_{t}$ is the restrained phosphorus concentration in synthetic solution $(\mathrm{mg} / \mathrm{L}), v$ is the volume of the solution (L), $w$ is the mass of produced sediment after phosphorus recovery $(\mathrm{mg})$, and $C_{0}$ is the initial phosphorus concentration $(\mathrm{mg} / \mathrm{L})$.

$4 \mathrm{~g}$ of samples (PCSH: $110^{\circ} \mathrm{C}, \mathrm{PCSH}: 140^{\circ} \mathrm{C}, \mathrm{PCSH}: 170^{\circ} \mathrm{C}$, and PCSH: $200^{\circ} \mathrm{C}$ ) were immersed in $1 \mathrm{~L}$ of demonized water, respectively, contained in a glass bottle, generating samples with a solution concentration of $4 \mathrm{~g} / \mathrm{L}$. The bottle was placed on an agitation table and shaken at $40 \mathrm{r} / \mathrm{min}$ under controlled temperature conditions $\left(20^{\circ} \mathrm{C}\right)$. Samples of solution were taken after $5,10,15,20,40,60$, and 80 mins of agitation. $\mathrm{Ca}^{2+}$ concentration of the samples was determined by EDTA titration (the relative error of data is $0.05 \%$ ).

2.3. Characterization Methods. XRD patterns were collected in an XD-2 instrument (Persee, China) using $\mathrm{Cu} \mathrm{K} \alpha$ radiation. FESEM images were collected on an S-4800 field emission scanning electron microscope (Hitachi, Japan). BET surface areas were measured by nitrogen adsorption at 77.35 K on an ASAP-2010 adsorption apparatus (Micromeritics, USA).

\section{Results and Discussion}

3.1. Phosphorus Recovery Performance of PCSH. The PCSH samples were separated from the removed synthetic solution after phosphorus removal, and these samples were added into synthetic solution with initial phosphorus concentration $100 \mathrm{mg} / \mathrm{L}$ again. This process was repeated for several times in order to explore the phosphorus recovery performance of PCSH. Changes of restrained phosphorus concentration are shown in Figure 1. There were great differences among the phosphorus recovery performance of these samples. Phosphorus content of PCSH: $110^{\circ} \mathrm{C}$ was only $6.49 \%$ after 7 times of phosphorus removal. Phosphorus content of PCSH: $140^{\circ} \mathrm{C}$ was $9.07 \%$ after 9 times of phosphorus removal. PCSH: $170^{\circ} \mathrm{C}$ could remove phosphorus repeated for 15 times, and phosphorus content of this sample reached $18.51 \%$. Phosphorus content of $\mathrm{PCSH}: 200^{\circ} \mathrm{C}$ was $12.92 \%$ after 11 times of phosphorus removal. Generally speaking, the material could be used as a high grade phosphorus ore when the phosphorus content of this material exceeds $15 \%$ [15]. Therefore, the hydrothermal temperature $170^{\circ} \mathrm{C}$ was beneficial for the PCSH to phosphorus removal. As seen in Figure 2, these samples reflected good phosphorus removal efficiency when $\mathrm{pH}$ values maintained 8.0 9.0. But with the times of phosphorus removal increased, $\mathrm{pH}$ values and the phosphorus removal efficiency of PCSH samples declined. The concentration of restrained phosphorus kept unchanged when $\mathrm{pH}$ values 


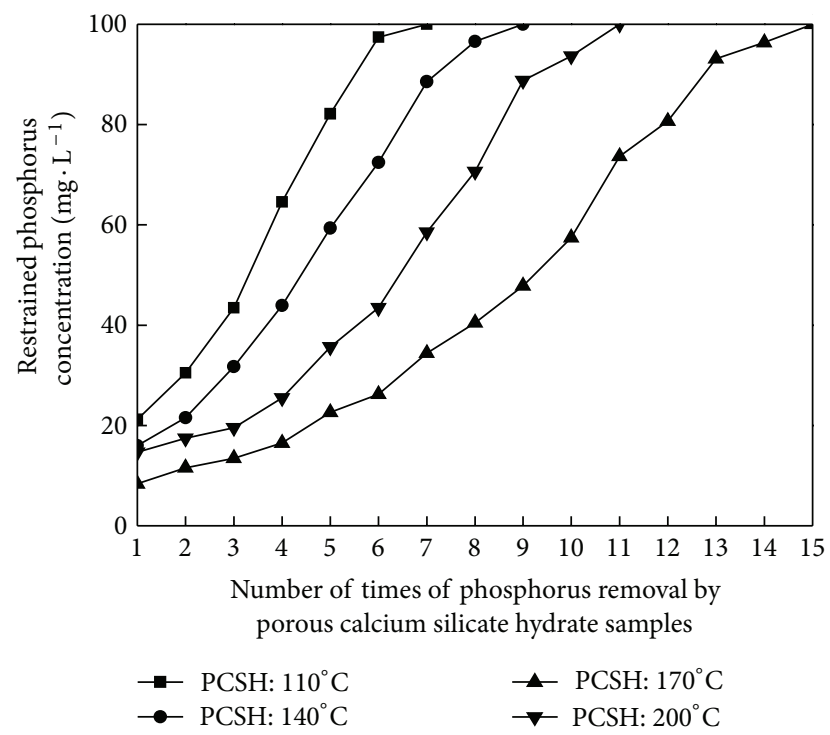

Figure 1: Changes of restrained phosphorus concentration by circulation of phosphorus removal.

declined to 7.0. This phenomenon showed that these samples had no phosphorus recovery performance on the condition of neutral. In contrast, PCSH: $170^{\circ} \mathrm{C}$ could maintain $\mathrm{pH}$ values at a range of 8.0 9.0 more effectively.

3.2. The Pore Structure and $\mathrm{Ca}^{2+}$ Release of PCSH. Specific surface area and pore size distribution were calculated by BET equation and Barrett-Joyner-Halenda method, respectively (Figure 3). The nitrogen sorption analysis was conducted to reveal the pore structure of calcium silicate hydrate. All three samples showed similar adsorption-desorption isotherms, which could be classified as type IV according to IUPAC nomenclature [16]. The results suggested the phenomenon of adsorption hysteresis loop. That mean mesopore or narrow gap pore existed on sample. Adsorption in mespore occurred mainly in medium pressure region $\left(0.4<P / P_{0}<0.9\right)$. When the hydrothermal temperature was lower than $170^{\circ} \mathrm{C}$, with the increase of hydrothermal temperature, the phenomenon of adsorption hysteresis loop became obvious and the adsorption curve increased. While the adsorption curve of PCSH: $200^{\circ} \mathrm{C}$ declined slightly, specific surface areas of PCSH: $110^{\circ} \mathrm{C}, \mathrm{PCSH}: 140^{\circ} \mathrm{C}$, PCSH: $170^{\circ} \mathrm{C}$, and PCSH: $200^{\circ} \mathrm{C}$ were $11.91,49.85,113.36$, and $59.67 \mathrm{~m}^{2} / \mathrm{g}$, respectively. Pore volumes of these samples were $0.07,0.15,0.53$, and $0.30 \mathrm{~cm}^{3} / \mathrm{g}$, respectively.

The morphology of PCSH: $110^{\circ} \mathrm{C}, \mathrm{PCSH}: 140^{\circ} \mathrm{C}, \mathrm{PCSH}$ : $170^{\circ} \mathrm{C}$, and PCSH: $200^{\circ} \mathrm{C}$ was examined by FESEM observations (Figure 4). It could be indicated from the photographs that the surface structure of PCSH: $110^{\circ} \mathrm{C}$ seems dense with pore size inhomogeneous distribution. The surface structure of PCSH: $140^{\circ} \mathrm{C}$ and PCSH: $200^{\circ} \mathrm{C}$ seems dense with pore size homogeneous distribution. In contrast, $\mathrm{PCSH}: 170^{\circ} \mathrm{C}$ possesses obverse fibrous-network structure with a large number of mesopores, and the particle size of spherical particle distributed from 25 to $30 \mu \mathrm{m}$ uniformly.

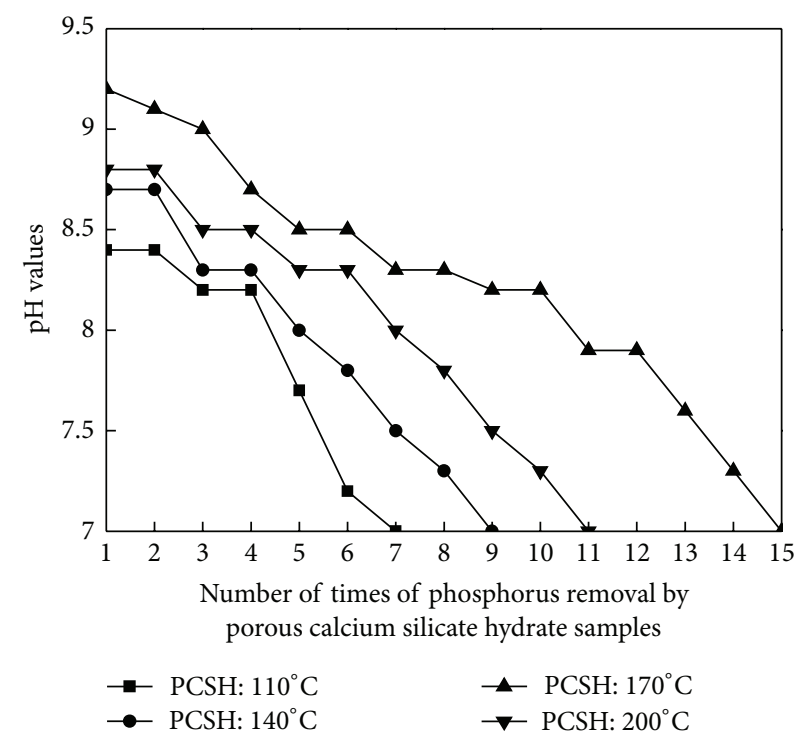

FIGURE 2: Changes of $\mathrm{pH}$ values by circulation of phosphorus removal.

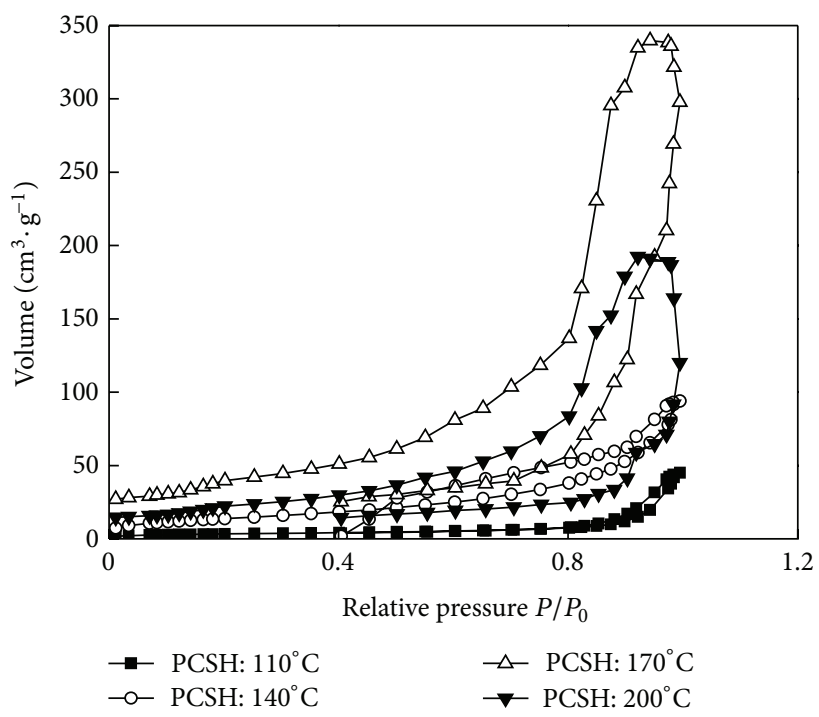

FIGURE 3: Nitrogen adsorption-adsorption isotherms on samples.

The experiments showed that $\mathrm{Ca}^{2+}$ concentration dissolved from PCSH: $110^{\circ} \mathrm{C}, \mathrm{PCSH}: 140^{\circ} \mathrm{C}, \mathrm{PCSH}: 170^{\circ} \mathrm{C}$, and PCSH: $200^{\circ} \mathrm{C}$ was $2.70,3.11,4.91$, and $3.76 \mathrm{mg} / \mathrm{g}$, respectively (Figure 5). This result showed that PCSH: $170^{\circ} \mathrm{C}$ reflected better performance of $\mathrm{Ca}^{2+}$ release. The experimental capacities of $\mathrm{Ca}^{2+}$ release were potted according to Avrami kinetic model as follows [17]:

$$
-\ln (1-x)=k t^{n},
$$

where $k$ is the kinetic constant, $n$ is the characteristic constant of solid, $t$ is the reaction time ( $\mathrm{min})$ and $x\left(x=C_{t} / C_{\max }, C_{t}\right.$ is concentration of time $t(\mathrm{mg} / \mathrm{L})$, and $C_{\max }$ is concentration of the maximum $(\mathrm{mg} / \mathrm{L})$ is the fraction conversion. The characteristic constant $n$ was 0.947 . The kinetic constants 


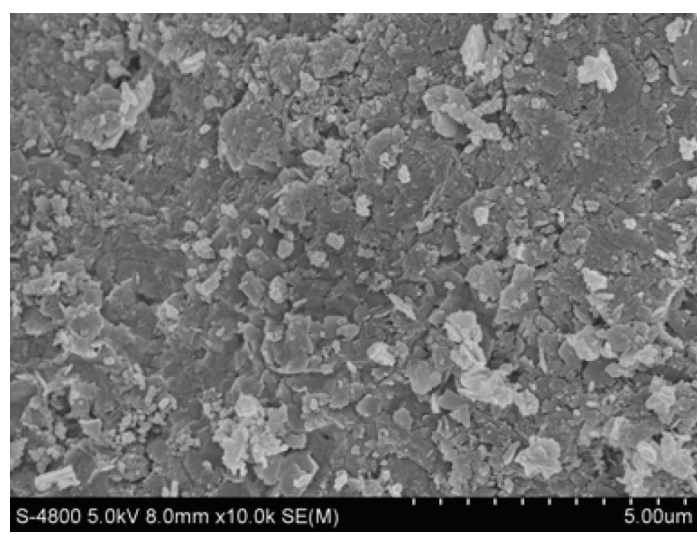

(a)

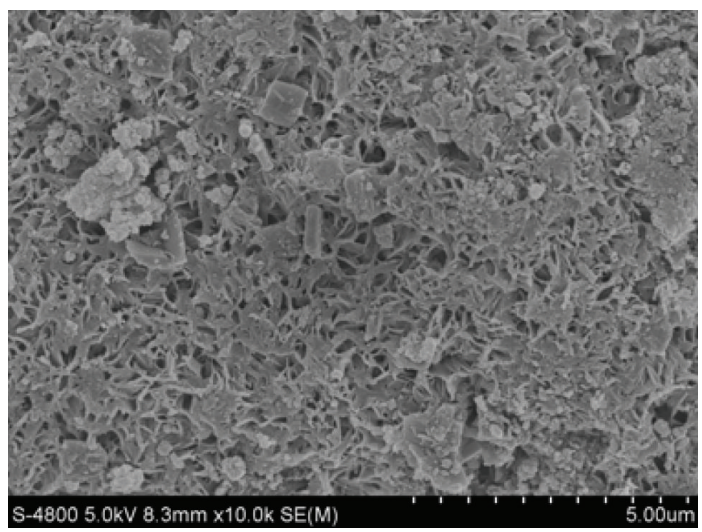

(c)

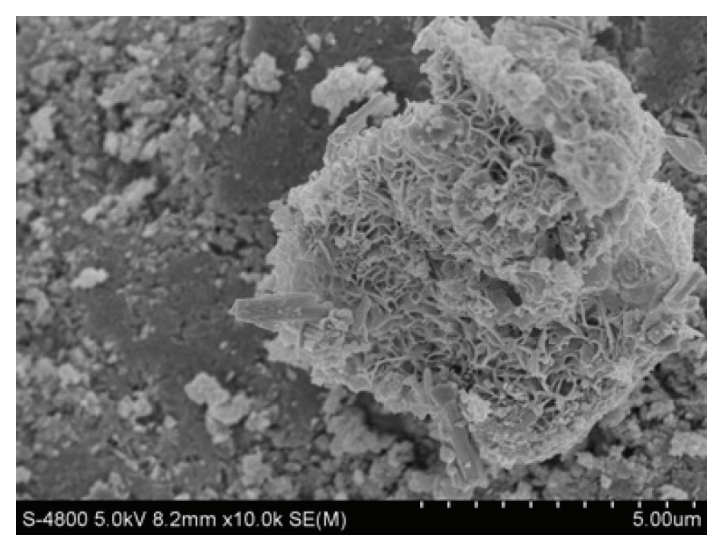

(b)

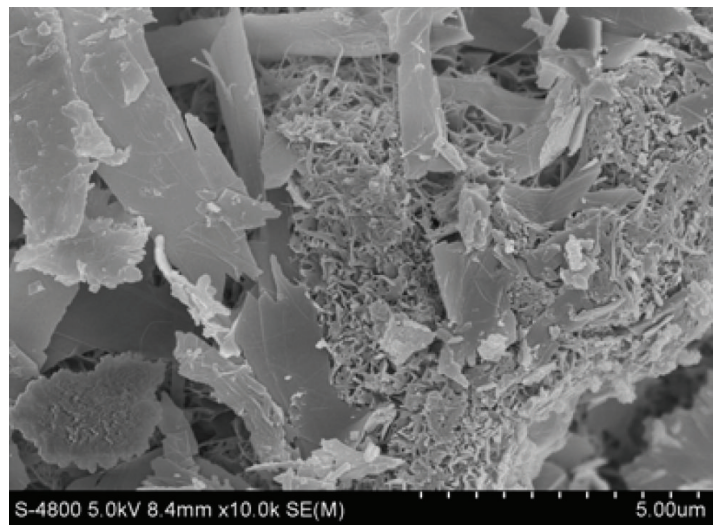

(d)

Figure 4: FESEM photographs of samples. (a) PCSH: $110^{\circ} \mathrm{C}$; (b) PCSH: $140^{\circ} \mathrm{C}$; (c) PCSH: $170^{\circ} \mathrm{C}$; (d) PCSH: $200^{\circ} \mathrm{C}$.

were determined by fitting the Avrami kinetic model to the experimental data obtained from Table 2. The high correlation coefficients $\left(R^{2}>0.9\right)$ indicated that this model could describe the law of $\mathrm{Ca}^{2+}$ release well. Combined with specific surface area $(S)$ of samples, a relationship between $k$ and $S$ could be established as follows:

$$
k=0.018 S^{0.315} \text {. }
$$

According to (3), specific surface area of samples and the rate of $\mathrm{Ca}^{2+}$ release were in good agreement with each other. The relationship between specific surface area and dissolved concentration of $\mathrm{Ca}^{2+}$ was obtained by substituting (3) into (2) as follows:

$$
-\ln (1-x)=0.018 S^{0.315} t^{0.947}
$$

According to (4), concentration of $\mathrm{Ca}^{2+}$ release was related to specific surface area. This result demonstrated the influence of hydrothermal temperature on phosphorus recovery performance. Hydrothermal temperature affected the pore structure and the performance of $\mathrm{Ca}^{2+}$ release. $\mathrm{Ca}^{2+}$ was released faster due to the larger specific surface area. Comparatively speaking, $\mathrm{PCSH}: 170^{\circ} \mathrm{C}$ possesses larger specific surface area. Porous structure provided a local condition to maintain a high concentration of $\mathrm{Ca}^{2+}$ release. $\mathrm{PCSH}$ : $170^{\circ} \mathrm{C}$ could release a suitable concentration of $\mathrm{Ca}^{2+}$ and $\mathrm{OH}^{-}$ to maintain the $\mathrm{pH}$ values during 8.0 9.0. Phosphate existed in the form of $\mathrm{HPO}_{4}{ }^{2-}$ in the range of these $\mathrm{pH}$ values [18]. $\mathrm{Ca}^{2+}, \mathrm{OH}^{-}$, and $\mathrm{HPO}_{4}{ }^{2-}$ formed a local condition with high concentration. This condition was beneficial to the formation of hydroxyapatite with $\mathrm{pH}=8.0 \sim 9.0$. The major reaction of the hydroxyapatite crystallization on PCSH crystal seed was as follows:

$$
5 \mathrm{Ca}^{2+}+\mathrm{OH}^{-}+3 \mathrm{HPO}_{4}{ }^{2-} \longrightarrow \mathrm{Ca}_{5}\left(\mathrm{PO}_{4}\right)_{3}(\mathrm{OH}) \downarrow+3 \mathrm{H}^{+} .
$$

3.3. Mechanism of Hydrothermal Temperature Effect on Phosphorus Recovery Performance. The mechanism of hydrothermal temperature effect on phosphorus recovery performance could be further investigated by XRD. The XRD patterns of PCSH samples were compared (Figure 6). The main phase of PCSH: $110^{\circ} \mathrm{C}$ was $\mathrm{SiO}_{2}$ (PDF card 18-1169), and this result indicated that carbide residue and white carbon black had not reacted completely. When the hydrothermal temperature increased to $140^{\circ} \mathrm{C}$, the main phase included Jennite (PDF card 18-1206, chemical formula $\left.\mathrm{Ca}_{9} \mathrm{Si}_{6} \mathrm{O}_{18}(\mathrm{OH})_{6} \cdot 8 \mathrm{H}_{2} \mathrm{O}\right)$ and $\mathrm{SiO}_{2}$, but the principal peaks of Jennite were not obvious. In this stage, a part of $\mathrm{SiO}_{2}$ had involved in the formation of Jennite, but the reaction was not completely, so 
TABLE 2: Correlation equations and rate constants for the Avrami kinetic model describing $\mathrm{Ca}^{2+}$ release.

\begin{tabular}{lccc}
\hline Samples & Avrami kinetic equations & Kinetic constant $(k)$ & Correlation coefficient $\left(R^{2}\right)$ \\
\hline PCSH: $110^{\circ} \mathrm{C}$ & $-\ln (1-x)=0.039 t^{0.947}$ & 0.039 & 0.973 \\
PCSH: $140^{\circ} \mathrm{C}$ & $-\ln (1-x)=0.052 t^{0.947}$ & 0.052 & 0.985 \\
PCSH: $170^{\circ} \mathrm{C}$ & $-\ln (1-x)=0.085 t^{0.947}$ & 0.085 & 0.998 \\
PCSH: $200^{\circ} \mathrm{C}$ & $-\ln (1-x)=0.066 t^{0.947}$ & 0.066 & 0.988 \\
\hline
\end{tabular}

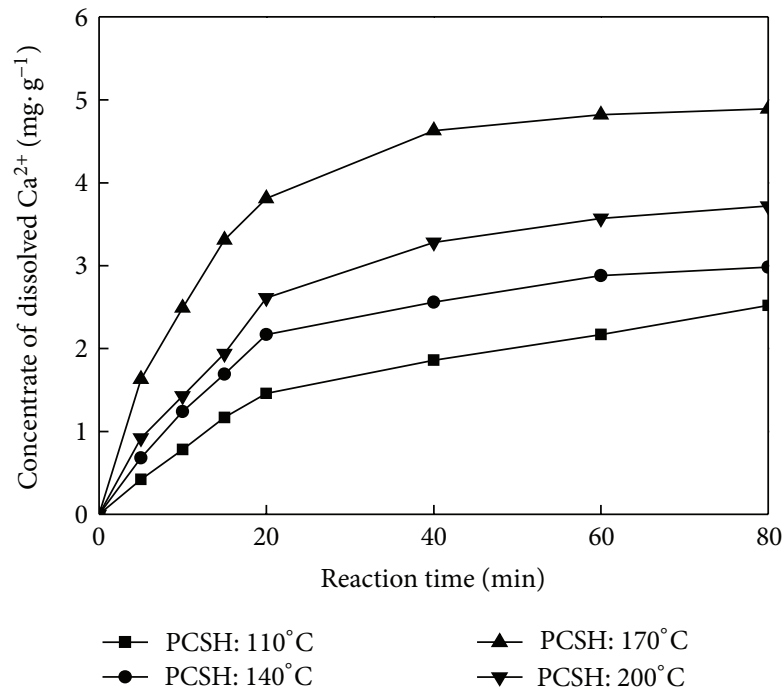

FIGURE 5: Concentrate of $\mathrm{Ca}^{2+}$ dissolved from samples.

the content of Jennite was low. When the hydrothermal temperature reached to $170^{\circ} \mathrm{C}$, the principal peaks of Jennite appeared instead of the principal peaks of $\mathrm{SiO}_{2}$ in the XRD patterns. This result indicated that the main component of PCSH: $170^{\circ} \mathrm{C}$ was Jennite. As the hydrothermal temperature heated to $200^{\circ} \mathrm{C}$, the production included jennite, xonotlite (PDF card 23-0125, chemical formula $\mathrm{Ca}_{6} \mathrm{Si}_{6} \mathrm{O}_{17}(\mathrm{OH})_{2}$ ), and $\mathrm{Ca}_{3} \mathrm{Si}_{2} \mathrm{O}_{7}$ (PDF card 11-0317).

As the siliceous material, white carbon black exhibited high activity [19]. Therefore, the hydrothermal reaction in the high-pressure reactor belonged to controlling solution reaction. The reaction process depended on the dissolution of $\mathrm{SiO}_{2}$, and the dissolution rate depended on the solubility of $\mathrm{SiO}_{2}$ in the white carbon black. Based on the above analysis, when the hydrothermal reaction was too low, $\mathrm{SiO}_{2}$ was difficult to dissolute, and formed a layer of rich silicon on the surface of samples. This condition made the pore structure of samples became dense. Rising the hydrothermal temperature could increase the solubility of $\mathrm{SiO}_{2}$. The solubility of white carbon black was low at atmospheric temperature and pressure, but the solubility increased with the increasing of hydrothermal temperature. Jennite formed when the hydrothermal temperature reached to $170^{\circ} \mathrm{C}$, and this material could dissolve a proper concentration of $\mathrm{Ca}^{2+}$ and $\mathrm{OH}^{-}$due to loose and porous structure. So PCSH: $170^{\circ} \mathrm{C}$ has better phosphorus recovery performance. The system of PCSH became instable due to a too high hydrothermal temperature, and multiple impurities appeared in this

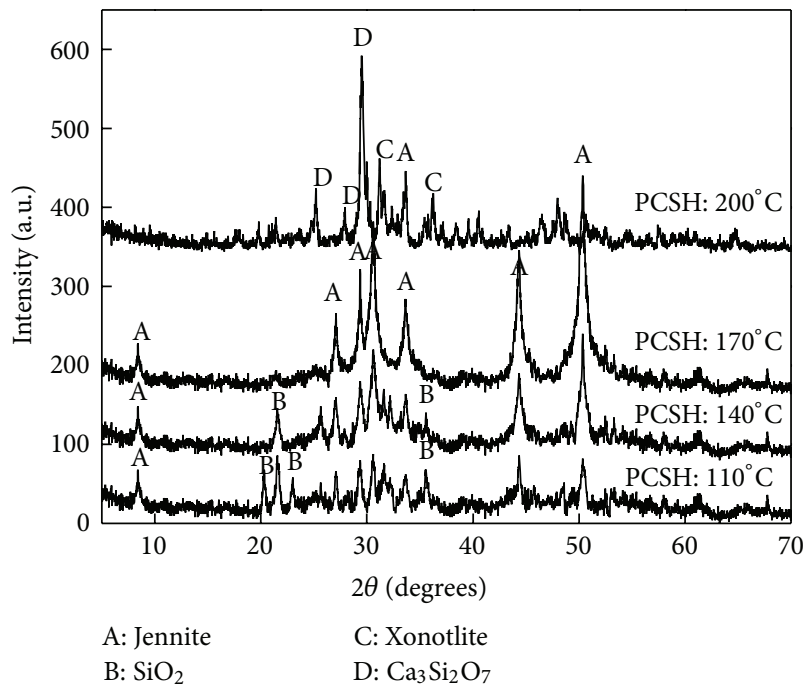

FIGURE 6: XRD patterns of samples.

system. The phosphorus recovery performance of the sample declined because the efficiency of $\mathrm{Ca}^{2+}$ and $\mathrm{OH}^{-}$release of the impurities was too low.

\section{Conclusions}

Porous calcium silicate hydrate was synthesized by carbide residue and white carbon black with a dynamic hydrothermal method. This material could be considered a tenable material for phosphorus removal and recovery from wastewater. Hydrothermal temperature showed significant influence on phosphorus recovery performance of PCSH. Hydrothermal temperature $170^{\circ} \mathrm{C}$ for $\mathrm{PCSH}$ was more proper to recover phosphorus. PCSH could recover phosphorus with content of $18.51 \%$.

The law of $\mathrm{Ca}^{2+}$ and $\mathrm{OH}^{-}$release was the key of phosphorus recovery efficiency. Changes of hydrothermal temperature led to the different pore structures. The increase of specific surface area and the increase in concentration of $\mathrm{Ca}^{2+}$ release were in good agreement with each other.

Further analysis by XRD indicated that hydrothermal reaction process depended on the dissolution of $\mathrm{SiO}_{2}$. And hydrothermal temperature affected the solubility of $\mathrm{SiO}_{2}$.

\section{References}

[1] E. H. Kim, S. B. Yim, H. C. Jung, and E. J. Lee, "Hydroxyapatite crystallization from a highly concentrated phosphate solution 
using powdered converter slag as a seed material," Journal of Hazardous Materials B, vol. 136, no. 3, pp. 690-697, 2006.

[2] J. Z. Zhou, L. L. Feng, J. Zhao et al., "Efficient and controllable phosphate removal on hydrocalumite by multi-step treatment based on $\mathrm{pH}$-dependent precipitation," Chemical Engineering Journal, vol. 185, pp. 219-225, 2012.

[3] P. Battistoni, P. Pavan, M. Prisciandaro, and F. Cecchi, "Struvite crystallization: a feasible and reliable way to fix phosphorus in anaerobic supernatants," Water Research, vol. 34, no. 11, pp. 3033-3041, 2000.

[4] P. Battistoni, A. de Angelis, P. Pavan, M. Prisciandaro, and F. Cecchi, "Phosphorus removal from a real anaerobic supernatant by struvite crystallization," Water Research, vol. 35, no. 9, pp. 2167-2178, 2001.

[5] D. Sugiyama and T. Fujita, "A thermodynamic model of dissolution and precipitation of calcium silicate hydrates," Cement and Concrete Research, vol. 36, no. 2, pp. 227-237, 2006.

[6] X. C. Chen, H. N. Kong, D. Y. Wu, X. Z. Wang, and Y. Lin, "Phosphate removal and recovery through crystallization of hydroxyapatite using xonotlite as seed crystal," Journal of Environmental Sciences, vol. 21, no. 5, pp. 575-580, 2009.

[7] J. J. Chen, J. J. Thomas, H. F. W. Taylor, and H. M. Jennings, "Solubility and structure of calcium silicate hydrate," Cement and Concrete Research, vol. 34, no. 9, pp. 1499-1519, 2004.

[8] F. Tariq, R. Haswell, P. D. Lee, and D. W. McComb, "Characterization of hierarchical pore structures in ceramics using multiscale tomography," Acta Materialia, vol. 59, no. 5, pp. 21092120, 2011.

[9] S. Sánchez-Salcedo, J. Werner, and M. Vallet-Regí, "Hierarchical pore structure of calcium phosphate scaffolds by a combination of gel-casting and multiple tape-casting methods," Acta Biomaterialia, vol. 4, no. 4, pp. 913-922, 2008.

[10] R. Siauciunas and K. Baltakys, "Formation of gyrolite during hydrothermal synthesis in the mixtures of $\mathrm{CaO}$ and amorphous $\mathrm{SiO}_{2}$ or quartz," Cement and Concrete Research, vol. 34, no. 11, pp. 2029-2036, 2004.

[11] S. Shaw, S. M. Clark, and C. M. B. Henderson, "Hydrothermal formation of the calcium silicate hydrates, tobermorite $\left(\mathrm{Ca}_{5} \mathrm{Si}_{6} \mathrm{O}_{16}(\mathrm{OH})_{2} \cdot 4 \mathrm{H}_{2} \mathrm{O}\right)$ and xonotlite $\left(\mathrm{Ca}_{6} \mathrm{Si}_{6} \mathrm{O}_{17}(\mathrm{OH})_{2}\right)$ : an in situ synchrotron study," Chemical Geology, vol. 167, no. 1-2, pp. 129-140, 2000.

[12] M. Li and H. Liang, "Formation of micro-porous spherical particles of Calcium Silicate (Xonotlite) in dynamic hydrothermal pocess," China Particuology, vol. 2, no. 3, pp. 124-127, 2004.

[13] A. A. P. Mansur and H. S. Mansur, "Preparation, characterization and cytocompatibility of bioactive coatings on porous calcium-silicate-hydrate scaffolds," Materials Science and Engineering C, vol. 30, no. 2, pp. 288-294, 2010.

[14] T. T. H. Bach, C. Cau Dit Coumes, I. Pochard, C. Mercierc, B. Reveld, and A. Nonatb, "Influence of temperature on the hydration products of low $\mathrm{pH}$ cements," Cement and Concrete Research, vol. 42, pp. 805-817, 2012.

[15] M. Sinirkaya, A. K. Özer, and M. S. Gülaboglu, "Investigation of the changes of $\mathrm{P}_{2} \mathrm{O}_{5}$ content of phosphate rock during simultaneous calcination/sulfation," Powder Technology, vol. 211, no. 1, pp. 72-76, 2011.

[16] Y. Geng, X. Wang, W. Chen, Q. Cai, C. Nan, and H. Li, "Synthesis, characterization and application of novel bicontinuous mesoporous silica with hierarchical pore structure," Materials Chemistry and Physics, vol. 116, no. 1, pp. 254-260, 2009.
[17] N. Demirkiran and A. Künkül, "Dissolution kinetics of ulexite in perchloric acid solutions," International Journal of Mineral Processing, vol. 83, no. 1-2, pp. 76-80, 2007.

[18] Y. Liu, X. Sheng, Y. H. Dong, and Y. J. Ma, "Removal of highconcentration phosphate by calcite: effect of sulfate and $\mathrm{pH}$," Desalination, vol. 289, pp. 66-71, 2012.

[19] M. Felipe-sese, D. Eliche-Quesada, and F. A. Corpas-lglesias, "The use of solid residues derived from different industrial activities to obtain calcium silicates for use as insulating construction materials," Ceramics International, vol. 37 , no. 8 , pp. 3019-3028, 2011. 

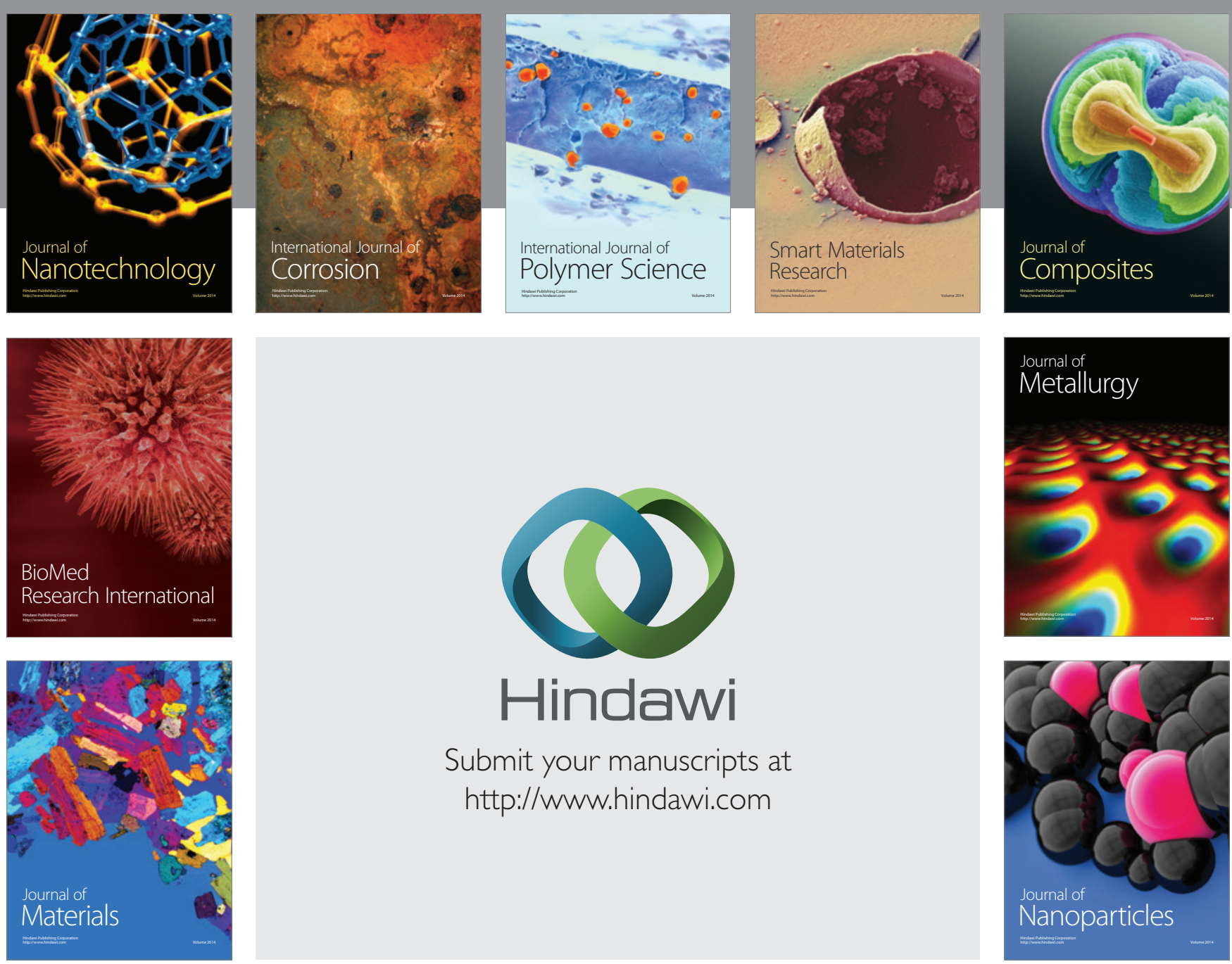

Submit your manuscripts at http://www.hindawi.com
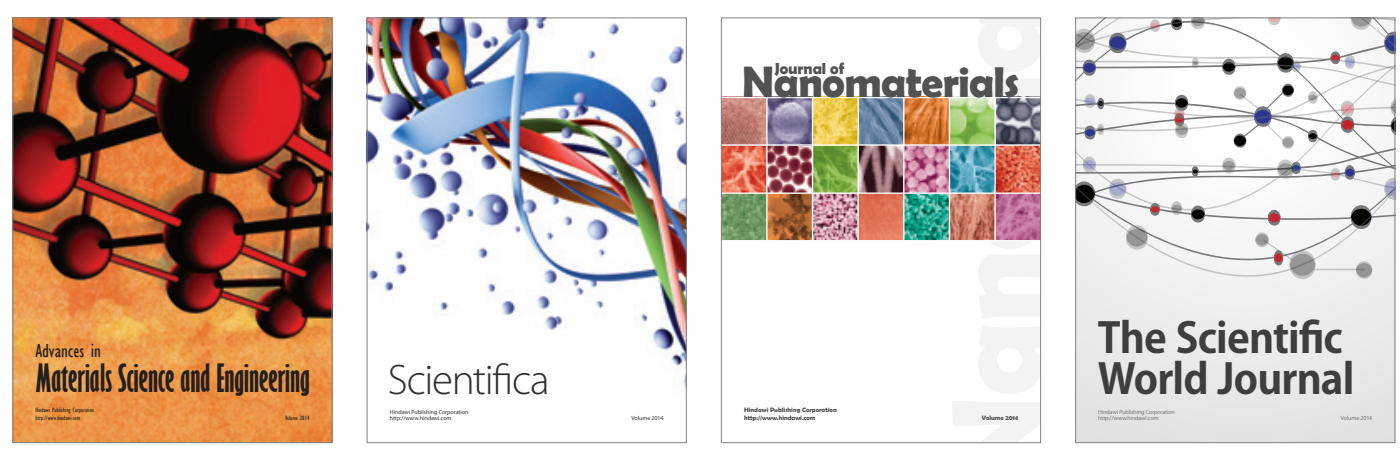

\section{The Scientific World Journal}
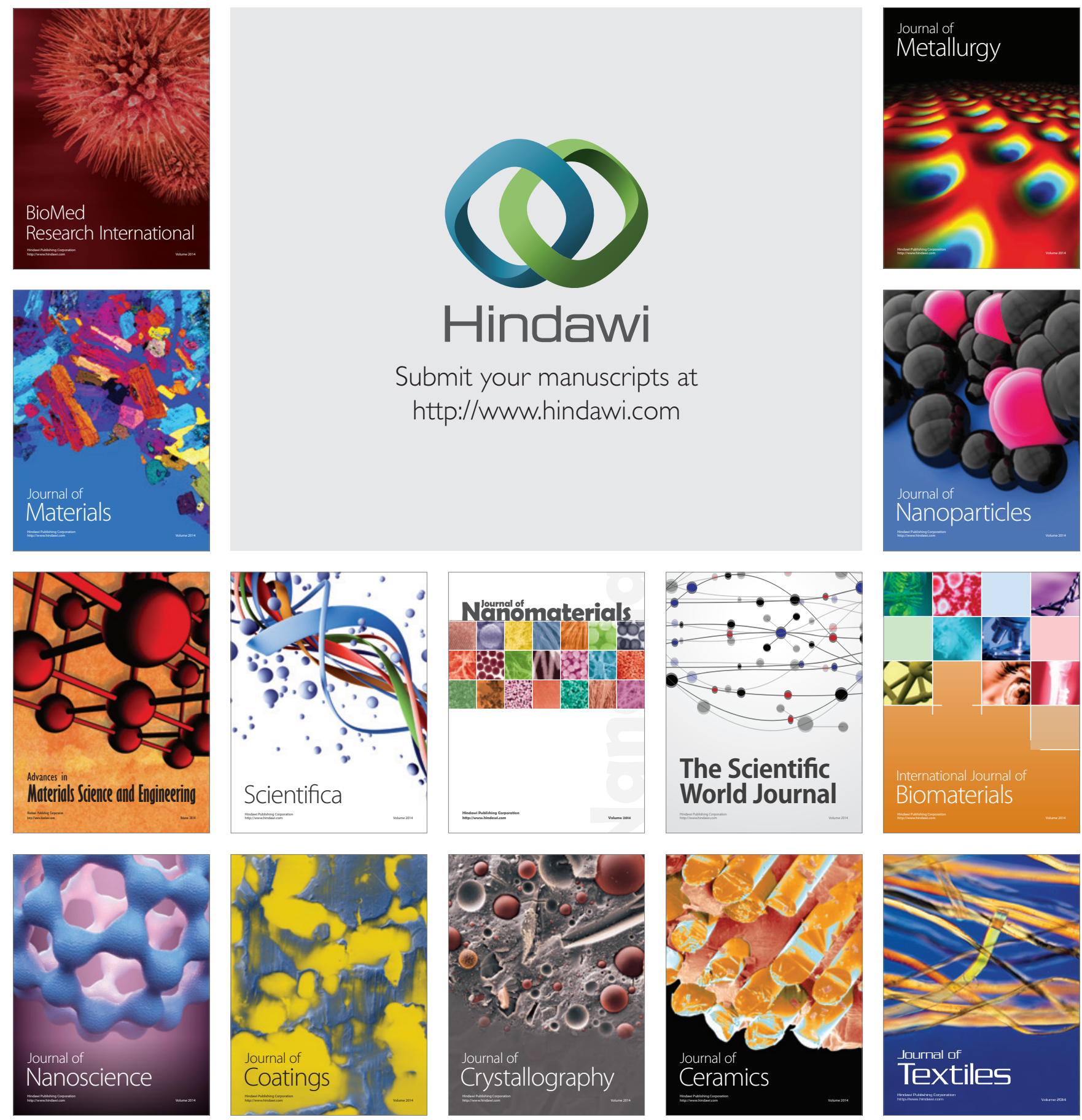